\title{
Effect of Motivational Interviewing on a Weight Loss Program Based on the Protection Motivation Theory
}

\author{
Kamal Mirkarimi ${ }^{1}$; Firoozeh Mostafavi ${ }^{1,}$; Samira Eshghinia ${ }^{2}$; Mohammad Ali Vakili ${ }^{3}$; \\ Rahman Berdi Ozouni-Davaji ${ }^{4}$; Mohammad Aryaie ${ }^{5}$
}

${ }^{1}$ Department of Health Education and Promotion, Faculty of Health, Isfahan University of Medical Sciences, Isfahan, IR Iran

${ }^{2}$ Metabolic Disorders Research Center, Golestan University of Medical Sciences, Gorgan, IR Iran

${ }^{3}$ Department of Health and Medical Sciences, Golestan University of Medical Sciences, Gorgan, IR Iran

${ }^{4}$ Health Management and Social Development Research Center, Golestan University of Medical Sciences, Gorgan, IR Iran

${ }_{5}^{5}$ Deputyship of Research, Golestan University of Medical Sciences, Gorgan, IR Iran

${ }^{*}$ Corresponding Author: Firoozeh Mostafavi, Department of Health Education and Promotion, Faculty of Health, Isfahan University of Medical Sciences, Isfahan, IR Iran. Tel:+98-9132118364, Fax: +98-1732421657, E-mail: f_mostafavi@yahoo.com

Received: September 9, 2014; Revised: September 29, 2014; Accepted: October 20, 2014

\begin{abstract}
Background: The prevalence of overweight and obesity is on the increase the world over, which imposes an ever-increasing burden on societies and health care systems.

Objectives:This study sought to investigate the effect of motivational interviewing(MI) on a weight-loss program based on the protection motivation theory (PMT).

Patients and Methods: This randomized clinical trial study, comprising pretest-posttest with a control group, was conducted on 150 overweight and obese women attending a private nutrition clinic for the first time. Samples were randomly selected using the clinic's records and then allocated to three groups (50 women in each group) receiving: 1 ) a standard weight-control program; 2) motivational interviewing; and 3) MI plus intention intervention. Data were collected using a researcher-made questionnaire through in-person interviews and were analyzed using SPSS (version 11) and statistical tests, including the Kruskal-Wallis test, one-way analysis of variance, paired t-test, and linear regression model.

Results: In the two intervention groups, the PMT construct scores, namely susceptibility ( $\mathrm{P}=0.001)$, severity $(\mathrm{P}=0.001)$, rewards $(\mathrm{P}=0.004)$, self-efficacy $(\mathrm{P}=0.001)$, response efficacy $(\mathrm{P}=0.001)$, and costs $(\mathrm{P}=0.014)$, were significantly increased compared to those in the control group. The anthropometric status was statistically significant in the MI group $(\mathrm{P}=0.001)$ and the MI plus intention-intervention group $(\mathrm{P}=$ $0.001)$ at 2 months' follow-up, while in the control group, weight was meaningfully different after the intervention $(\mathrm{P}=0.027)$. Weight was different between the groups after the intervention, with the Tukey test demonstrating that the differences were statistically significant between the control group and the MI group.

Conclusions: Our results demonstrated that MI, combined with the implementation of intention intervention, increased weight loss and PMT construct scores in our study population.
\end{abstract}

Keywords: Motivational Interviewing; Weight Loss; Humans

\section{Background}

Obesity is one of the most critical public health problems and imposes a preventable threat to human health status across the world (1). The morbidity risk of cardiovascular disease, dyslipidemia, hypertension, and type II diabetes mellitus has risen due to overweight and obesity (2). According to reports by the World Health Organization (WHO), obesity affects around 300 million people around the globe (3). The Iranian Ministry of Health reported that cardiovascular disease accounts for $35 \%$ of the total mortality rates (2). Currently, the prevalence rate of obesity in Iran is estimated at $22.3 \%$ (4). Women may be at greater risk of overweight and obesity than men $(5,6)$ and, as such, more prone to such diseases as hypertension during pregnancy; thromboembolism; diabetes mellitus
(4, 7-10); and breast, cervical, and colon cancer (11). The prevention and treatment of overweight and obesity is a multi-factorial health problem that requires action from policy makers to individuals. A large number of studies have shown that effective weight-loss programs are clinic-based using face-to-face behavioral programs through weekly visits $(12,13)$.

Motivational interviewing (MI) is a client-centered and directive technique aimed at resolving the individual's ambivalence and augmenting intrinsic motivation (14). MI has widely been applied in health arenas with effective results (14), as is attested to by a nearly two-fold increase in the number of relevant scientific publications in the past 3 years (15). In recent years, MI has been drawn upon for

Copyright ( 2015, Iranian Red Crescent Medical Journal. This is an open-access article distributed under the terms of the Creative Commons Attribution-NonCommercial 4.0 International License (http://creativecommons.org/licenses/by-nc/4.0/) which permits copy and redistribute the material just in noncommercial usages, provided the original work is properly cited. 
the treatment of chronic diseases. A significant number of patients with such diseases need behavioral and lifestyle modifications so as to be able to regain their health; nevertheless, unfortunately only a few practical approaches are currently available to help professionals and clients in this field (16) and the achievement rate in the treatment of the aforementioned health problems using traditional processes is not satisfactory (17). For instance, a study showed that traditional treatment processes were able to control only $30 \%$ of hypertension patients (18). In another study, 50\% of the individuals who participated in a physical activity program quit it within 3 to 6 months; in addition, the adherence rate to weight-loss strategies was less than 50\% after 6 months (19). Elsewhere, only 25\% of the subjects recruited in a study had achieved weight loss 18 months post intervention (20). With respect to MI, the existing literature abounds with conflicting reports: for all the studies reporting the superiority of MI over traditional approaches to behavioral change (21-23), there are those that have found no differences of note between these modalities $(22,24)$. MI challenges traditional treatments by recommending that volunteers know what is beneficial to them and that specialists help them to select more applicable methods (25). Despite the rapid growth of MI application and its spread to different areas of health, there is a dearth of information on this novel approach in Iran, where overweight and obesity are widely deemed a serious lifestyle-related problem (17).

The protection motivation theory (PMT) was originally developed in 1975 by Ronald Rogers to describe the process behind the attitudinal and behavioral changes that people undertake when faced with a real or perceived threat to their health (26). To the best of our knowledge, there has been previously no study to sufficiently probe into the effects of MI on overweight and obesity based on the PMT in Iran.

\section{Objectives}

In light of the fact that the PMT is a reliable predictor of dietary (27) and physical activity (28), we assumed that it would also be a good predictor of overweight and obesity and sought to investigate the effect of MI on a weight-loss program based on the PMT.

\section{Patients and Methods}

\subsection{Study Design}

This single-blind randomized clinical trial study, comprising pretest-posttest with a control group, was conducted between September 2013 and April 2014 in the Iranian city of Gorgan. The study protocol was granted an Iranian Registry of Clinical Trial Code (IRCT2014051817736N1). Subjects were recruited from among women attending a nutrition clinic for the first time using the clinic's records via the convenient sampling method. Selection bias was controlled via random block allocation, there being 25 blocks (each block containing 6 persons), and the process was repeated twice and letters $A, B$, and $C$ were used. The selection of the numbers of the blocks was done randomly using the Statistical Package for the Social Sciences (SPSS) (version 18). The participants were thereafter randomly allocated to three groups receiving: MI $(n=50)$, MI plus intention intervention $(\mathrm{n}=50)$, and a standard weightcontrol program (control group, $\mathrm{n}=50$ ). For the purposes of blind allocation, block size was not presented. The MI sessions were designed based on five sessions of group MI (29) for between 7 and 10 women per session. In the MI plus intention-intervention group, the subjects received MI together with an intention-intervention program that encompassed a weight-loss plan based on a well-defined schedule (Figure 1).

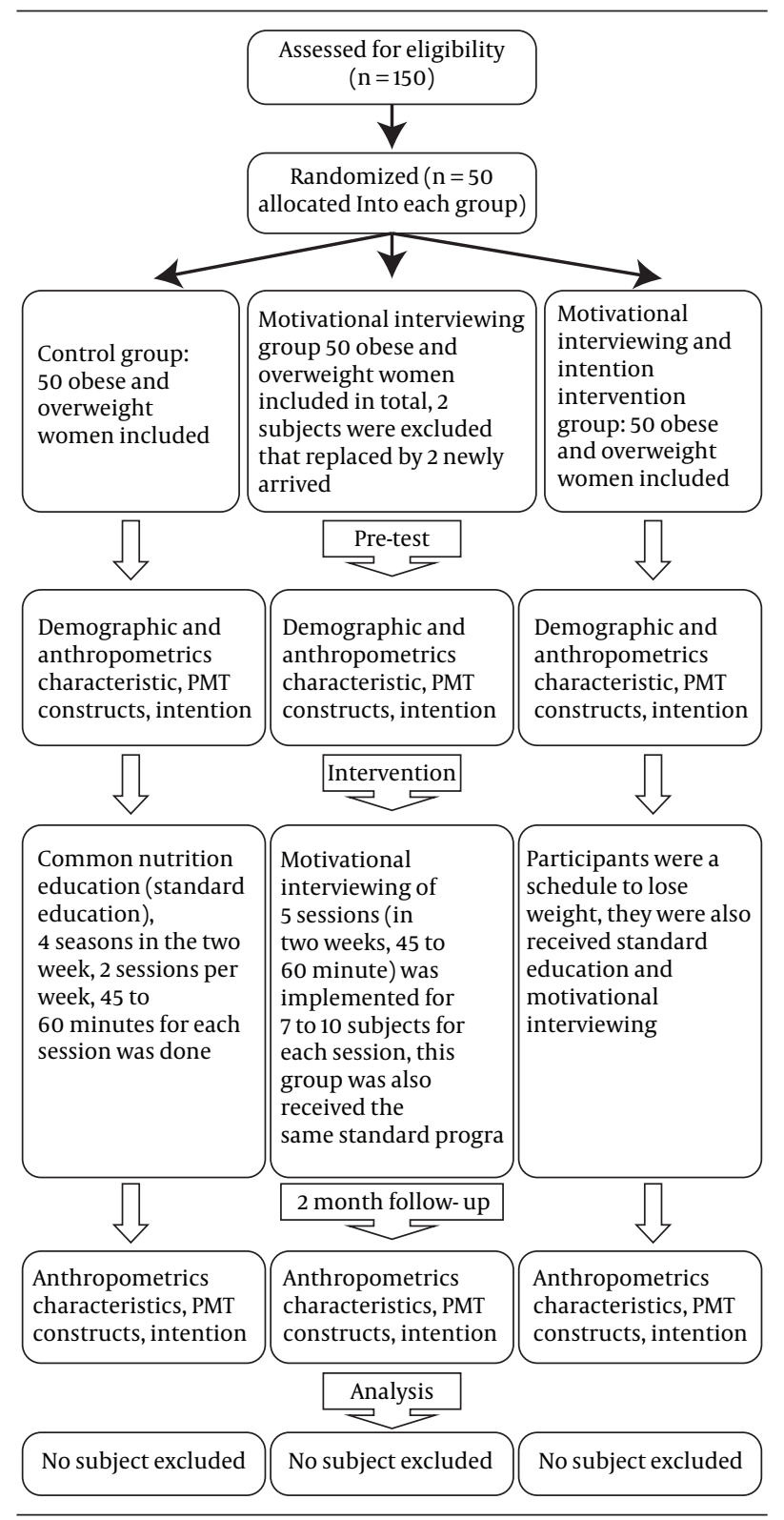

Figure 1. Flow Chart of Randomized Clinical Trial (RCT) 


\subsection{Group of Standard Program}

The women in this group were given a standard education program, comprised of a total of four sessions in 2 weeks (two sessions of 45 to 60 minutes per week), covering diet and exercise by a nutritionist, a psychologist, and a health education specialist. At the end of the sessions, the participants had access to the researchers to ask questions.

\subsection{Motivational Interviewing Group}

This group was given five sessions of MI by a psychologist. Between 7 and 10 subjects took part in each session. The participants were given a pamphlet designed based on the PMT constructs discussing overweight and obesity and the effects of nutrition behavior change on the control and prevention thereof. Similar to the control group, the members of this group also received the four sessions of the standard education program.

\subsection{Motivational Interviewing plus Intention-In- tervention Group}

The members of this group received the standard education as well as the MI programs exactly the same as the MI group, but they were given a detailed timeline to which they were supposed to adhere. The participants were told that success was more likely if they committed themselves to an exact dietary program based on a welldefined schedule. Then they were asked to write and keep this sentence: "I will try to lose one $\mathrm{kg}$ by consuming 3 to 4 portions of fruit and 4 to 5 portions of vegetables and by reducing fatty foods as is recommended by the guidelines in the next 2 weeks."

\subsection{Participants}

The inclusion criteria were comprised of being female, body mass index (BMI) ranging between 25 and 29.9 (overweight) and 30 and 35 (obese), lack of illnesses such as diabetes mellitus, cardiovascular diseases, and thyroid diseases, and consumption of drugs that may interfere with appetite and weight. The exclusion criteria consisted of pregnancy, disruptive diseases during intervention, inability to exercise, and absence more than two sessions (standard and MI). In total, 150 eligible subjects (50 for each of the three groups) were included in our study. Two women in the MI group were excluded due to absence more than two sessions and were replaced by newly arrived women. None of the study participants in the three groups received drugs or other treatments.

\subsection{Sample Size}

According to a related study (30) and the estimation of a mean of 2.4 , standard deviation of $2.34,95 \%$ confidence interval (CI), 90\% test power, 1.8 effect size, and also $25 \%$ losses of samples, we considered an initial sample vol- ume of 43 and finally 50 subjects in each of the three groups. Accordingly, the current study was performed on a sample of 150 women.

\subsection{Measures}

An in-person interview was carried out by trained interviewers using a structured and researcher- made questionnaire. The interviewers were educated in the field of health care and were certified before conducting the interviews.

\subsection{Variables Definition}

General obesity was assessed according to the BMI $\left(\mathrm{kg} / \mathrm{m}^{2}\right)$. Overweight and obesity were described based on the general criteria of the WHO as $25 \leq \mathrm{BMI}<30$ for overweight and BMI $\geq 30$ for obesity (1). Education levels were classified into four categories: elementary school; middle school; high school; and university. Regarding occupation, the study population was categorized as housewives, farmers, retired, unemployed, and other. Marital status was also classified as single and married.

\subsection{Instrument}

Data were collected using a researcher-made questionnaire based on the PMT in nine sections: 1 ) demographic characteristics; 2) knowledge (12 questions; scores: "no" and "I don't know" = 0 and "yes" =1; points ranging from 0 to 12 ); 3 ) perceived self-efficacy (11 questions with a 10-item scale; scores $=$ one to 10 ; range $=$ 11 to 110 ); 4 ) intention (11 questions; range $=11$ to 44 ); 5 ) perceived susceptibility ( 9 questions; range $=9$ to $36) ; 6$ ) perceived severity (4 questions; range $=4$ to 16 ); 7) perceived rewards ( 8 questions; range $=8$ to 32 ); 8 ) perceived response efficacy ( 8 questions; range $=8$ to 32 ); and 9) perceived costs (12 questions; range $=12$ to 48). Questions such as intention, perceived susceptibility, perceived severity, perceived rewards, perceived response efficacy and, in brief, perceived costs were all scored between one and 4 based on a 4-point Likert scale, including “completely agree”, "agree”, “disagree”, and "completely disagree". Our literature search yielded no related questionnaires, so a new one was developed by the researchers for the present study. The face validity of the tool was confirmed by 5 specialists and its content validity by 10 specialists. In brief, the content validity rate and content validity index were calculated. The reliability of the questionnaire was evaluated using internal homogeneity and Cronbach's alpha, and the values of these coefficients were also calculated for every structure. The highest and lowest Cronbach's alphas were for perceived self-efficacy (0.91) and perceived susceptibility (0.72), respectively. Cronbach's alphas were $0.87,0.82,0.85,0.88$, and 0.89 for perceived severity, perceived costs, intention, perceived response efficacy, and perceived rewards, correspondingly. 


\subsection{Data Analysis}

Descriptive analysis was utilized to describe the mean and standard deviation of the anthropometric and demographic characteristics. The three groups were different at baseline based on the PMT constructs. Afterward, the post-intervention score was subtracted from the baseline score for each construct and the variables of knowledge, intention, perceived susceptibility, perceived severity, perceived costs, perceived rewards, perceived response efficacy, and perceived self-efficacy were scored in order to compare the groups. If there was no normal distribution in the scores according to the Kolmogorov-Simonov test, the Kruskal-Wallis test would be used to compare the constructs between all the groups. To compare the anthropometric characteristics, the paired t-test was employed at baseline and at 2 months' follow-up. Additionally, to predict the effects of the constructs on intention, after controlling the other constructs, a multiple linear regression model was used. A P value $<0.05$ was considered statistically significant.

\section{Results}

\subsection{Participants}

A sample of 150 overweight and obese women was recruited for the survey. Of these 150 participants, the three groups of control, MI, and MI plus intention intervention were each allocated 50 subjects. The means and demographic characteristics of the study groups are summarized in Table 1. The women's age ranged from 19 to 67, with a mean of $38.45 \pm 9.49$ years. The mean of the BMI was $28.7 \pm 2$ at baseline. The majority of the participants (46.7\%; $n=70)$ had university qualifications, 60.7\% ( $n=$ 91) were housewives, and $78.7 \%(n=118)$ were married. At baseline, the three study groups did not differ in terms of the BMI and weight, whereas they were different as regards the constructs of the PMT.

The Kruskal-Wallis test was implemented to compare all the three groups regarding the PMT constructs. As is demonstrated in Table 2, the results showed that the constructs were different after the intervention inasmuch as the construct values, with the exception of rewards ( $\mathrm{P}=$ $0.004)$ and costs $(P=0.014)$, were significantly increased in the two intervention groups compared to those in the control group $(\mathrm{P}=0.001)$.

As is depicted in Table 3, the paired t-test reported that the anthropometric status was statistically significant in both intervention groups at 2 months' follow-up $(\mathrm{P}<$ $0.05)$, whereas in the control group, weight was meaningfully different after the intervention $(P<0.05)$. The ANOVA test demonstrated no differences between the three groups at baseline regarding the BMI and weight; nevertheless, it showed that weight was different between the groups after the intervention. According to the Tukey test, these differences were statistically significant between the control and MI groups $(\mathrm{P}<0.038)$ and between the MI group and the MI plus intention-intervention group $(\mathrm{P}<0.004)$. The BMI was also different between the three groups, with the Tukey test showing a statistically significant difference between the control and MI groups $(\mathrm{P}<0.003)$.

\begin{tabular}{|c|c|c|c|}
\hline Variables & Motivational Interviewing Group & Motivation-Intention Group & Control Group \\
\hline Age, $y$ & $37.9 \pm 8.9$ & $39.5 \pm 10.3$ & $37.9 \pm 9.1$ \\
\hline Body mass index, $\mathrm{kg} / \mathrm{m}^{2}$ & $28.2 \pm 2.23$ & $29.01 \pm 2.09$ & $28.8 \pm 1.59$ \\
\hline Weight, kg & $74.2 \pm 6.95$ & $77.34 \pm 6.89$ & $75.9 \pm 6.05$ \\
\hline Height, $\mathrm{cm}$ & $162.1 \pm 7.17$ & $163.1 \pm 5.54$ & $162.2 \pm 6.23$ \\
\hline Waist circumference, $\mathrm{cm}$ & $80.36 \pm 6.98$ & $84.52 \pm 9.84$ & $89.02 \pm 10.77$ \\
\hline Waist-to-hip ratio & $0.81 \pm 0.045$ & $0.80 \pm 0.042$ & $0.78 \pm 0.049$ \\
\hline \multicolumn{4}{|l|}{ Education } \\
\hline Elementary school & $4(8)$ & $-c$ & $2(4)$ \\
\hline Middle school & $5(10)$ & $8(16)$ & $5(10)$ \\
\hline High school & $15(30)$ & $20(40)$ & $21(42)$ \\
\hline University & $26(52)$ & $22(44)$ & $22(44)$ \\
\hline \multicolumn{4}{|l|}{ Job } \\
\hline Housewife & $31(62)$ & $31(62)$ & $29(58)$ \\
\hline Retired & $2(4)$ & $4(8)$ & $2(4)$ \\
\hline Unemployed & $11(22)$ & $6(12)$ & $9(18)$ \\
\hline Other & $6(12)$ & $9(18)$ & $10(20)$ \\
\hline \multicolumn{4}{|l|}{ Marital status } \\
\hline Single & $11(22)$ & $9(18)$ & $12(24)$ \\
\hline Married & $39(78)$ & $41(82)$ & $38(76)$ \\
\hline
\end{tabular}

\footnotetext{
a Data are presented as mean \pm standard deviation or No. (\%).

b $\mathrm{n}=50$.

c There were not participants with elementary level in this group.
} 
Mirkarimi Ket al.

\begin{tabular}{|c|c|c|c|c|}
\hline Constructs & Mean Rank & Median & IQR & P Value \\
\hline Knowledge difference & & & & 0.001 \\
\hline Control & 29.86 & 8.34 & 16.67 & \\
\hline Motivational interviewing & 105.66 & 41.67 & 25 & \\
\hline Motivation-intention & 90.98 & 33.34 & 18.75 & \\
\hline Intention difference & & & & 0.001 \\
\hline Control & 27.30 & 3.03 & 9.09 & \\
\hline Motivational interviewing & 110.87 & 27.27 & 12.13 & \\
\hline Motivation-intention & 88.33 & 21.21 & 9.85 & \\
\hline Perceived susceptibility difference & & & & 0.001 \\
\hline Control & 60.64 & 3.70 & 11.12 & \\
\hline Motivational interviewing & 99.98 & 11.12 & 14.83 & \\
\hline Motivation-intention & 65.88 & 7.40 & 11.12 & \\
\hline Perceived severity difference & & & & 0.001 \\
\hline Control & 47.73 & 8.34 & 10.42 & \\
\hline Motivational interviewing & 101.16 & 25 & 16.67 & \\
\hline Motivation-intention & 77.61 & 16.67 & 16.66 & \\
\hline Perceived rewards difference & & & & 0.004 \\
\hline Control & 91.91 & 4.17 & 16.67 & \\
\hline Motivational interviewing & 66.83 & -4.17 & 16.67 & \\
\hline Motivation-intention & 67.76 & -4.17 & 16.67 & \\
\hline Perceived self-efficacy difference & & & & 0.001 \\
\hline Control & 25.50 & 10.10 & 5.05 & \\
\hline Motivational interviewing & 95.21 & 31.31 & 7.32 & \\
\hline Motivation-intention & 105.79 & 32.32 & 7.58 & \\
\hline Perceived response efficacy difference & & & & 0.001 \\
\hline Control & 59.48 & 8.34 & 8.33 & \\
\hline Motivational interviewing & 115.23 & 20.84 & 16.67 & \\
\hline Motivation-intention & 51.79 & 4.17 & 12.50 & \\
\hline Perceived cost difference & & & & 0.014 \\
\hline Control & 86.84 & 0.00 & 6.25 & \\
\hline Motivational interviewing & 61.91 & -5.55 & 11.12 & \\
\hline Motivation-intention & 77.75 & -2.78 & 13.89 & \\
\hline
\end{tabular}

${ }^{a} \mathrm{n}=50$.

Table 4 shows that all the constructs of the PMT predicted the women's intention when they were entered in the model separately. However, after adjustment, three of them, name- ly perceived self-efficacy $(\mathrm{P}=0.001)$, perceived response effi$\operatorname{cacy}(P=0.001)$, and perceived rewards $(P=0.022)$, were able to significantly predict the subjects' intention. 
Mirkarimi Ket al.

\begin{tabular}{|c|c|c|c|}
\hline \multirow[t]{2}{*}{ Variables } & \multicolumn{2}{|c|}{ Intervention } & \multirow[t]{2}{*}{ P Value } \\
\hline & Baseline & 2 Months' Follow-up & \\
\hline \multicolumn{4}{|l|}{ Body mass index $\left(\mathrm{kg} / \mathrm{m}^{2}\right)$} \\
\hline Control & $28.84 \pm 1.59$ & $28.85 \pm 1.53$ & 0.953 \\
\hline Motivational interviewing & $28.25 \pm 2.22$ & $27.58 \pm 2.11$ & 0.001 \\
\hline Motivation-intention & $29.01 \pm 2.09$ & $28.00 \pm 2.04$ & 0.001 \\
\hline \multicolumn{4}{|l|}{ Weight (kg) } \\
\hline Control & $75.91 \pm 6.05$ & $75.70 \pm 6.10$ & 0.027 \\
\hline Motivational interviewing & $74.25 \pm 6.95$ & $72.50 \pm 6.40$ & 0.001 \\
\hline Motivation-intention & $77.33 \pm 6.89$ & $76.74 \pm 6.85$ & 0.001 \\
\hline
\end{tabular}

a Data are presented as Mean \pm SD.

$\mathrm{b} \mathrm{n}=50$.

\begin{tabular}{lcccc}
\hline Table 4. Predicting Intention Based on the Constructs Using Adjusted and Unadjusted Regression Models \\
\hline Construct & \multicolumn{2}{c}{ Unadjusted } & \multicolumn{2}{c}{ Adjusted } \\
\cline { 2 - 5 } & $\beta$ & P Value & $\beta$ & PValue \\
\hline Perceived susceptibility & 0.27 & 0.001 & 0.033 & 0.557 \\
Perceived severity & 0.41 & 0.001 & 0.094 & 0.106 \\
Perceived rewards & -0.26 & 0.001 & -0.124 & 0.022 \\
Perceived response efficacy & 0.88 & 0.001 & 0.283 & 0.001 \\
Perceived self-efficacy & 0.70 & 0.001 & 0.653 & 0.001 \\
Perceived costs & -0.17 & 0.036 & -0.073 & 0.167 \\
\hline
\end{tabular}

\section{Discussion}

The first aim of the present study was to explore the effect of a PMT-based MI on changes in the PMT constructs and weight-loss intention. The second purpose was to investigate whether the PMT-based MI in tandem with an intention-intervention program would enhance the efficacy of a weight-loss program.

Our results demonstrated that all the three groups lost a considerable amount of weight and that the two intervention groups significantly lost more weight than the control group. However, with regard to the BMI, the control group was not different from the two intervention groups after the intervention $(\mathrm{P}<0.953)$, although the BMI had a decrease in both intervention groups $(\mathrm{P}<$ 0.001). According to Table 2, all the three groups were significantly different post intervention. The two intervention groups showed statistically meaningful improvement by comparison with the control group regarding all the constructs and variables. The improvement in the control group was expected since its members received a standard weight-control program. The predictive power of the PMT in terms of weight-loss intention was tested by entering all the constructs of the theory in the regression model through the backward regression model, separately. The results revealed that all the constructs had a significant relation with intention. Next, using an adjusting model, the three constructs of perceived rewards, perceived self-efficacy, and perceived response efficacy were able to predict the women's intention. Selfefficacy was the most effective predictor of intention $(\beta=$ $0.65)$, followed by perceived response efficacy $(\beta=0.28)$ and perceived rewards $(\beta=-0.12)$. Park et al. (31) explored functional food consumption behavior and reported that self-efficacy and perceived response efficacy were significant predictors of intention, which chimes in with our results The authors also reported that severity and vulnerability were also not significant predictors of intention, which is concordant with our results but discordant with the results of some other investigations (32-34). The nonsignificant relation between the other constructs and intention can be explained by the notion that in Iranian society women value rewards because they are extremely influenced by subjective norms (family or friends) and that the mean age among our female subjects was 38.45 years. Indeed, people in this age group have fewer health problems and may have a lower tendency to care about their health status, which can predict the nonsignificant relationship between severity and susceptibility.

Our literature review yielded no studies exploring the 
effects of implementing a combination of MI and intention intervention on overweight and obesity and that there are only a few investigations into physical activity (35-37) which have reported a notable improvement in exercise behavior thanks to a combination of these two interventions. These results are also in accordance with our findings. Huang (37) combined the two aforementioned interventions and reported a significant difference regarding overweight and obesity on the basis of the PMT constructs, including perceived vulnerability, self-efficacy, response costs, intention, and reported physical activity behavior, while there was no considerable difference concerning physical activity in their two study groups (37). According to Dochy et al. (38), prior higher knowledge is strongly associated with enhanced perception of the nature of overweight or obesity; consequently, it might lead to higher scores of constructs. Because the vast majority of the members of the three groups in our study had university qualifications, it should come as no surprise that there was a significant relationship the between women's intention and the PMT constructs.

The fact that the current survey examined only women may limit the generalizability of the results beyond this sample. It is also probable that our study population's high level of knowledge also impacted their response. The bulk of the research conducted hitherto in this field has focused on adults; it seems beneficial to investigate overweight and obesity in children and adolescents given the widespread weight-related health problems across the globe. On the other hand, the salient strong point of our study is that whereas there are only a few studies on the use of MI, as a novel method, to effect behavioral change, ours is a randomized clinical trial with a follow-up of the samples receiving education on MI.

In our study population, MI not only increased the PMT construct scores but decreased the weight as well. Furthermore, MI combined with the implementation of intention intervention increased weight loss and the PMT construct scores. Both intervention groups had significantly augmented PMT construct scores and reduced weight in comparison with the control group.

\section{Acknowledgements}

The authors wish to thank Isfahan University of Medical Sciences for its financial and scientific support and all the women recruited in this survey.

\section{Authors' Contributions}

Study concept and design: Firoozeh Mostafavi, Kamal Mirkarimi; Acquisition of data: Rahman Berdi OzouniDavaji, Kamal Mirkarimi; Analysis and interpretation of data: Mohammad Ali Vakili; Drafting of the manuscript: Firoozeh Mostafavi, Kamal Mirkarimi; Critical revision of the manuscript for important intellectual content: Firoozeh Mostafavi, Kamal Mirkarimi and Mohammad Ali Vakili; Statistical analysis: Mohammad Ali Vakili; Ad- ministrative, technical, and material support: Firoozeh Mostafavi and Samira Eshghinia; Study supervision: Firoozeh Mostafavi and Samira Eshghinia.

\section{Funding/Support}

This study was supported by Isfahan University of Medical Sciences.

\section{References}

1. Lee SA, Wen W, Xu WH, Zheng W, Li H, Yang G, et al. Prevalence of obesity and correlations with lifestyle and dietary factors in Chinese men. Obesity (Silver Spring). 2008;16(6):1440-7.

2. Sotoudeh G, Khosravi S, Khajehnasiri F, Khalkhali HR. High prevalence of overweight and obesity in women of Islamshahr, Iran. Asia Pac J Clin Nutr. 2005;14(2):169-72.

3. Lippa NC, Sanderson SC. Impact of information about obesity genomics on the stigmatization of overweight individuals: an experimental study. Obesity (Silver Spring). 2012;20(12):2367-76.

4. Kaiser P. Obesity as a risk factor for cesarean in a low-risk population. Obstetrics \& Gynecol. 2001;97(1):39-43.

5. Wolongevicz DM, Zhu L, Pencina MJ, Kimokoti RW, Newby PK, D'Agostino RB, etal. Diet quality and obesity in women: the Framingham Nutrition Studies. BrJ Nutr. 2010;103(8):1223-9.

6. Ryan D. Obesity in women: a life cycle of medical risk. Int J Obes (Lond). 2007;31 Suppl 2:S3-7.

7. Young TK, Woodmansee B. Factors that are associated with cesarean delivery in a large private practice: the importance of prepregnancy body mass index and weight gain. Am J Obstet Gynecol. 2002;187(2):312-8.

8. Ehrenberg HM, Durnwald CP, Catalano P, Mercer BM. The influence of obesity and diabetes on the risk of cesarean delivery. Am JObstet Gynecol. 2004;191(3):969-74.

9. Galtier-Dereure F, Boegner C, Bringer J. Obesity and pregnancy: complications and cost. Am J Clin Nutr. 2000;71(5 Suppl):1242S-8S.

10. Rosenberg TJ, Garbers S, Chavkin W, Chiasson MA. Prepregnancy weight and adverse perinatal outcomes in an ethnically diverse population. Obstet Gynecol. 2003;102(5 Pt1):1022-7.

11. Osorio-Costa F, Rocha GZ, Dias MM, Carvalheira JB. Epidemiological and molecular mechanisms aspects linking obesity and cancer. Arq Bras Endocrinol Metabol. 2009;53(2):213-26.

12. Wadden TA, Foster GD. Behavioral Treatment of Obesity. Med Clin of North A. 2000;84(2):441-61.

13. Haas WC, Moore JB, Kaplan M, Lazorick S. Outcomes from a medical weight loss program: primary care clinics versus weight loss clinics. Am J Med. 2012;125(6):603 e7-11.

14. Martins RK, McNeil DW. Review of Motivational Interviewing in promoting health behaviors. Clin Psychol Rev. 2009;29(4):283-93.

15. Cox WM, Klinger E. Handbook of motivational counseling: Concepts, approaches, and assessment.England:John Wiley \& Sons; 2004.

16. Ossman SS. Motivational interviewing: a process to encourage behavioral change. Nephrol Nurs J. 2004;31(3):346-7.

17. Navidian A, Abedi MR, Baghban I, Fatehizadeh M, Poursharifi H. Effect of motivational interviewing on blood pressure of referents suffering from hypertension. Kowsar Med J. 2010;15(2):115-21.

18. Rollnick S, Miller WR, Butler C. Motivational interviewing in health care: helping patients change behavior. New York: Guilford Press; 2008.

19. Westen D, Morrison K. A multidimensional meta-analysis of treatments for depression, panic, and generalized anxiety disorder: an empirical examination of the status of empirically supported therapies. J Consult Clin Psychol. 2001;69(6):875-99.

20. Dusek JA, Hibberd PL, Buczynski B, Chang BH, Dusek KC, Johnston JM, et al. Stress management versus lifestyle modification on systolic hypertension and medication elimination: a randomized trial.J Altern Complement Med. 2008;14(2):129-38.

21. Dunn C, Deroo L, Rivara FP. The use of brief interventions adapted from motivational interviewing across behavioral domains: a systematic review. Addiction. 2001;96(12):1725-42. 


\section{Mirkarimi Ket al.}

22. Burke BL, Arkowitz H, Menchola M. The efficacy of motivational interviewing: a meta-analysis of controlled clinical trials. J Consult Clin Psychol. 2003;71(5):843-61.

23. Rubak S, Sandbaek A, Lauritzen T, Christensen B. Motivational interviewing: a systematic review and meta-analysis. Br J Gen Pract. 2005;55(513):305-12.

24. Burke BL, Dunn CW, Atkins DC, Phelps JS. The Emerging Evidence Base for Motivational Interviewing: A Meta-Analytic and Qualitative Inquiry. J Cognitive Psychotherapy. 2004;18(4):309-22.

25. Rollnick S, Mason P, Butler C. Health behavior change: a guide for practitioners. Elsevier Health Sci; 1999.

26. Ralph AF, Ager B, Bell ML, Collins IM, Andrews L, Tucker K, et al. Women's preferences for selective estrogen reuptake modulators: an investigation using protection motivation theory. $\mathrm{Pa}$ tient Educ Couns. 2014;96(1):106-12.

27. Yoon E. Food defense management plan implementation intention: An application of protection motivation theory. ProQuest; 2007.

28. Redd BR. Using the protection motivation theory to examine the effects of obesity fear arousal on the physical activity of young adult female college students. 2012. Available from: http://digitalcommons.wayne.edu/oa_dissertations/582/.

29. Moazzami Z, Soltanian AR. Correct body posture in nurses: an application ofmotivational interviewing. Sci Research. 2013;3(3):466-73.

30. Khezeli M, Ramezankhani A, Bakhtiyari M. Effect of Education on Nutritional Knowledge and Stages of Fruit and Vegetable Consumption in Elders Based on Stages of Change Model. J Mazand Univ Med Sic. 2012;22(91):90-100.
31. Park OH, Hoover L, Dodd T, Huffman L, Feng D. The Use of the Modified Protection Motivation Theory to Explore Adult Consumers' Functional Foods Consumption Behavior. 2011. Available from: http:| scholarworks.umass.edu/cgi/viewcontent.cgi?article=1234\&con text=gradconf_hospitality.

32. Henson S, Cranfield J, Herath D. Understanding consumer receptivity towards foods and non-prescription pills containing phytosterols as a means to offset the risk of cardiovascular disease: an application of protection motivation theory. I J Consumer Studies. 2010;34(1):28-37.

33. Davis R, Anderson O, Vincent C, Miles K, Sevdalis N. Predictors of hospitalized patients' intentions to prevent healthcare harm: a cross sectional survey. Int J Nurs Stud. 2012;49(4):407-15.

34. Tyc VL, Hadley W, Allen D, Varnell S, Ey S, Rai SN, et al. Predictors of smoking intentions and smoking status among nonsmoking and smoking adolescents. Addict Behav. 2004;29(6):1143-7.

35. Milne S, Orbell S, Sheeran P. Combining motivational and volitional interventions to promote exercise participation: protection motivation theory and implementation intentions. $\mathrm{Br} J$ Health Psychol. 2002;7(Pt 2):163-84.

36. Zhang Y, Cooke R. Using a combined motivational and volitional intervention to promote exercise and healthy dietary behaviour among undergraduates. Diabetes Res Clin Pract. 2012;95(2):215-23.

37. Huang C. Effects of motivational and volitional interventions on adolescents'physical activity behavior. Utah: Uni Utah; 2012.

38. Dochy F, Segers M, Buehl MM. The relation between assessment practices and outcomes of studies: The case of research on prior knowledge. Review of educational research. 1999;69(2):86-145. 